\title{
Getting Found, Staying \\ Found, Increasing Impact
}

Enhancing Readership and
Preserving Content for OJS Journals

Kevin Stranack

Public Knowledge Project 
Open Journal Systems is a research and development initiative of the Public Knowledge Project. Its continuing development is currently overseen by a partnership among the University of British Columbia, the Simon Fraser University Library, and the Canadian Center for Studies in Publishing.

For more information, see the Public Knowledge Project web site: http://pkp.sfu.ca

This work is licensed under the Creative Commons Attribution-NonCommercialNoDerivs License. To view a copy of this license, visit http://creativecommons.org/ licenses/by-nc-nd/2.0/ca/ or send a letter to Creative Commons, 559 Nathan Abbott Way, Stanford, California 94305, USA.

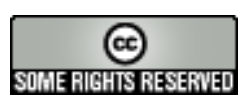




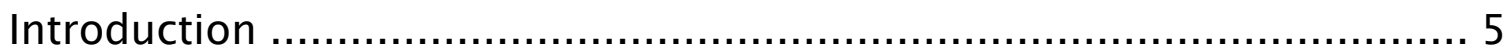

Getting Found: Building the Visibility of Your Journal ......................... 6

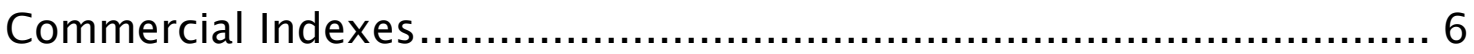

What are Commercial Indexes? ................................................ 6

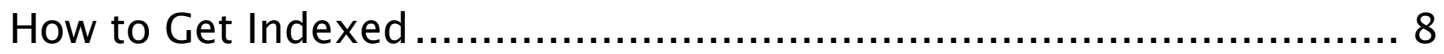

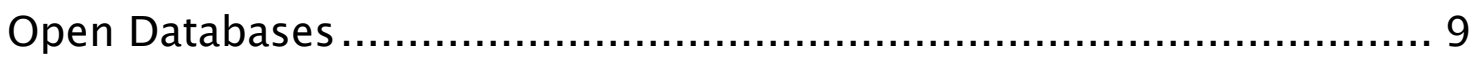

What are Open Databases? ........................................................ 9

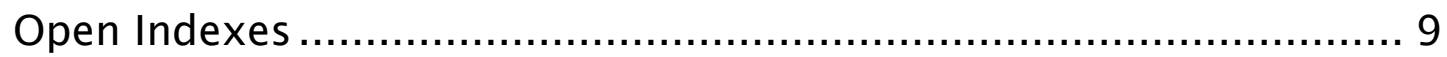

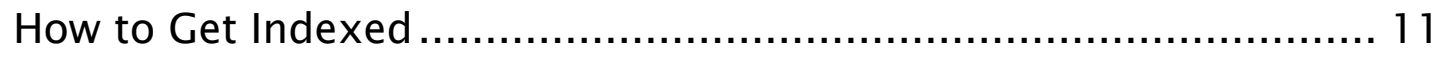

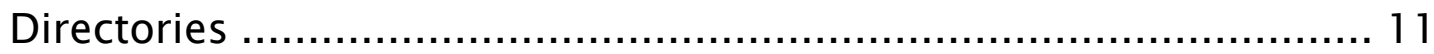

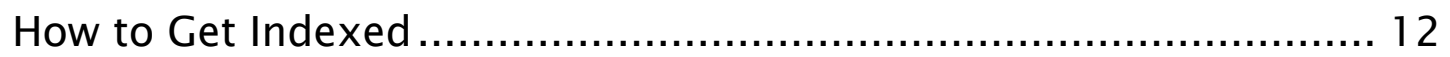

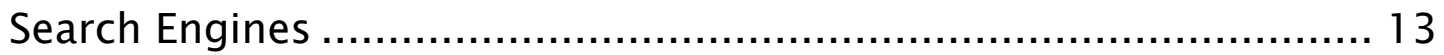

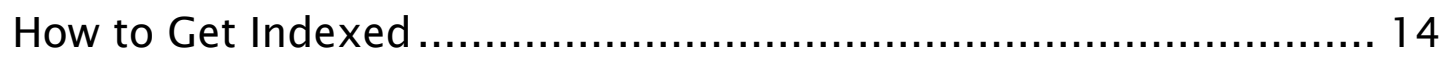

Open Archive Metadata Harvesters............................................. 15

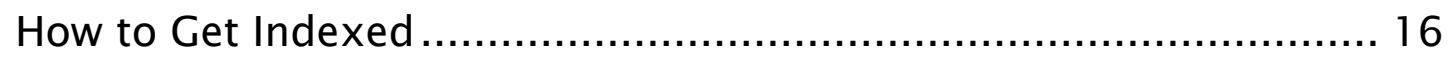

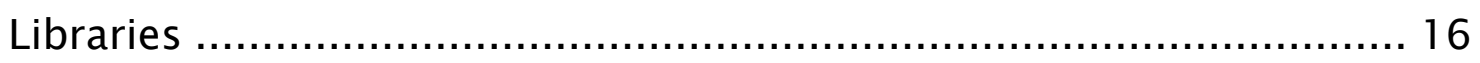

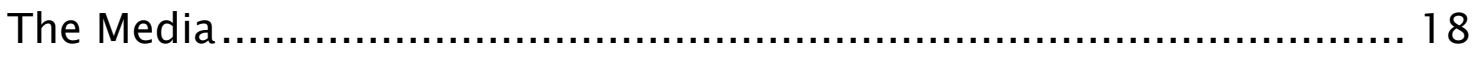

How to Write a Press Release .................................................... 19

How to Distribute a Press Release ............................................. 20

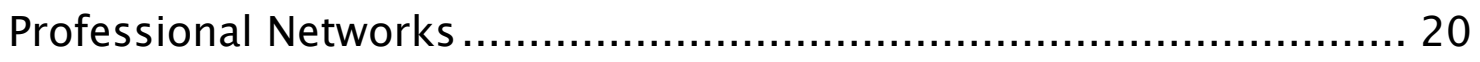

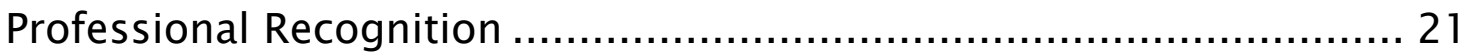

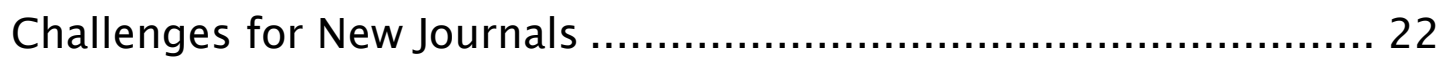

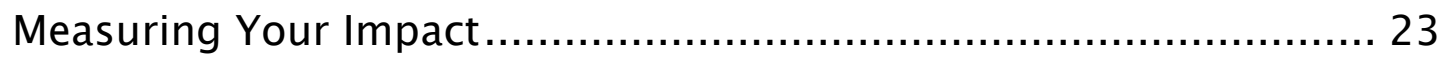


Journal Standards and Identifiers ............................................. 25

International Standard Serials Number ...................................... 25

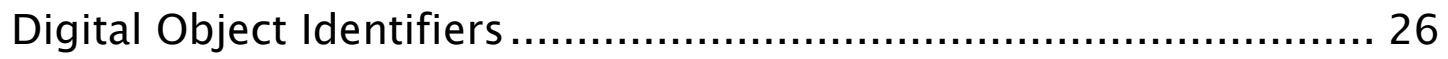

Staying Found: Building Reliable and Ongoing Content ....................... 29

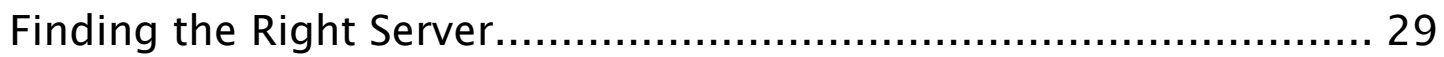

LOCKSS (Lots of Copies Keeps Stuff Safe) .................................... 32

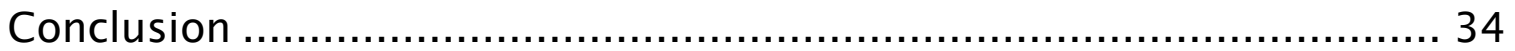

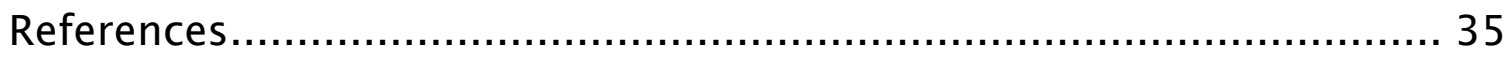

Appendix A: Indexing Criteria ...................................................... 36

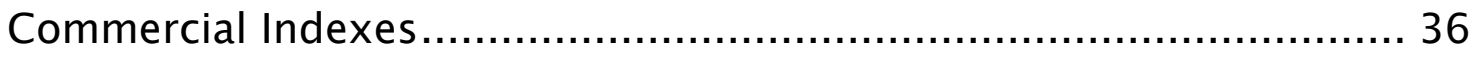

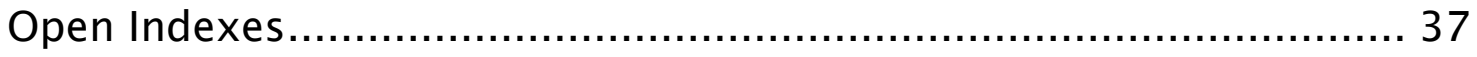

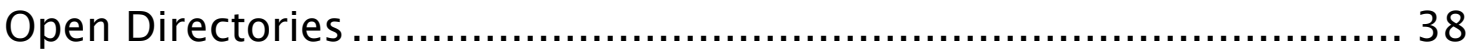

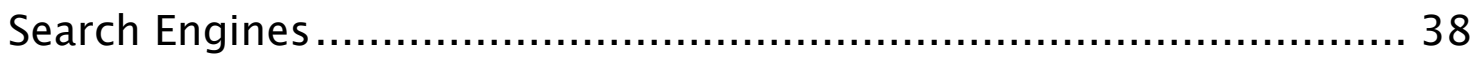

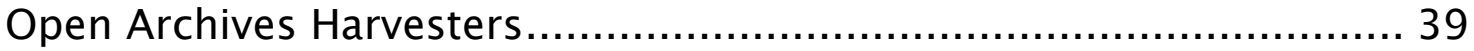

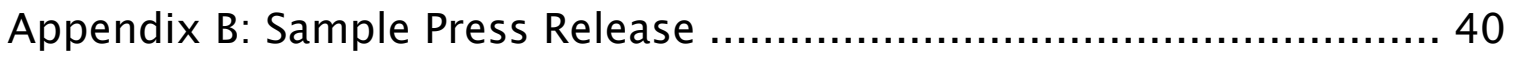




\section{Introduction}

Publishing a journal is about more than simply putting ink to paper (or pixels to screen). It is a collaboration between you and your readers. Two critical aspects of this relationship are, first, making your journal visible to your prospective audience. By putting your content online and making it freely available through open access, you will be reaching of millions of people around the world. But if they don't know you are out there, they will not be able to become part of your scholarly community.

Second, once you have your content in place, and have established an audience of dedicated readers, you will want to ensure that your journal is always available - 24 hours a day, 7 days a week, 365 days a year. Unlike paper publications, electronic journals can disappear rather easily, either temporarily or permanently. Regular downtime caused by an unreliable server environment, or worse, complete loss of your content due to a lack of any kind of backup or preservation strategy, can seriously undermine your credibility with your readers, or even totally wipe out all of the work you and your collaborators have done together.

Fortunately, this booklet will outline some simple procedures to help you increase your journal's 'findability' and build a wider audience, and will also show you how to ensure reliable and ongoing access to your valuable content. 


\section{Getting Found: Building the Visibility of}

\section{Your Journal}

The success of your journal depends on developing a regular readership, who will become part of your scholarly community, cite your content in their own work, and tell others about the value of your publication. To do this, however, they will first need to be able to find you. This section examines a variety of ways to increase the 'findability' of your journal, through the use of commercial indexes, open databases, libraries, the media, professional networks, and professional recognition.

\section{Commercial Indexes}

\section{What are Commercial Indexes?}

Commercial indexes are collections of journal citation details (such as author names, article title, journal title, volume and issue numbers, abstracts, etc. - also known as "metadata") maintained in a central, searchable database. As commercial services, these indexes are only available with a paid subscription, and are often accessed by readers through their library. A significant portion of any academic library budget goes toward making these commercial products freely available to their 
faculty and students. One of the most influential indexes is Thomson Scientific's Web of Science (http:/ / scientific.thomson.com/products /wos/).

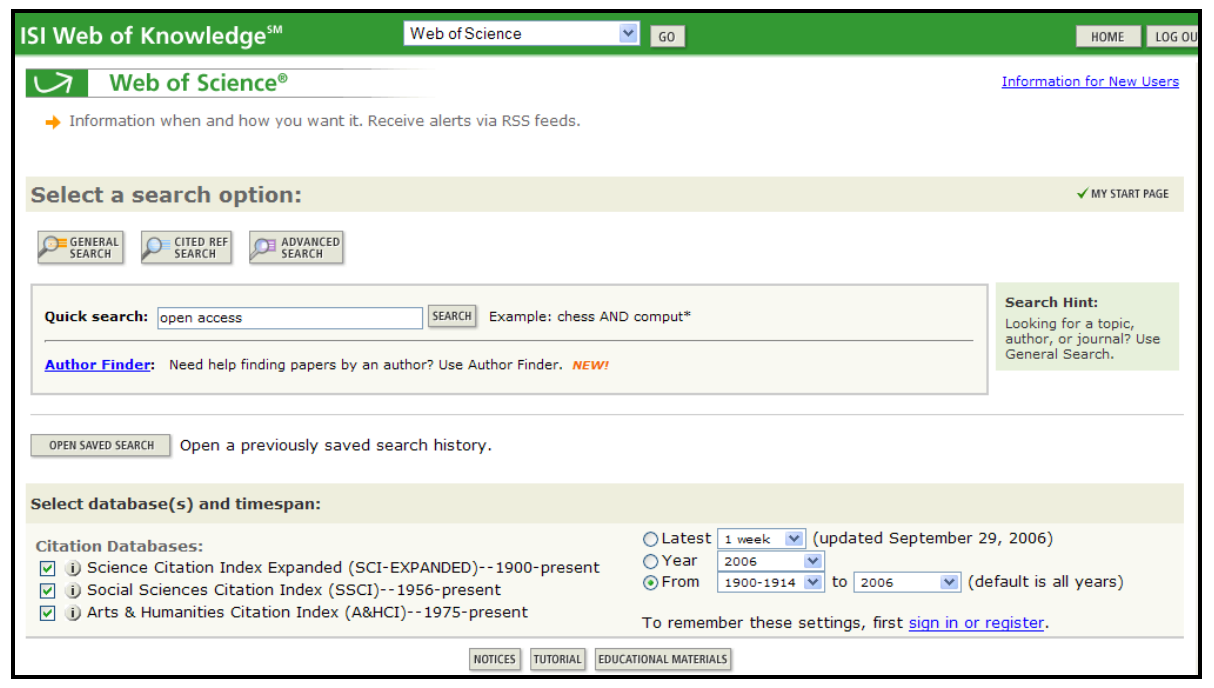

Figure 1: Web of Science

Some indexes may be focused on a single discipline, such as Psyclnfo (http://www.apa.org/psycinfo/) for psychology, while others are multidisciplinary (Elsevier's Scopus - http://www.scopus.com/). Some combine information from hundreds of journals, and others may only include the metadata from a few. Some indexes are produced by scholarly societies or non-profit organizations and others by for-profit businesses. Commercial indexes are often the most important way for readers to find your content, and getting included in one or more of them is important for your journal's success. 


\section{How to Get Indexed}

To take advantage of these powerful research tools, and "be recognized as an authoritative, high-quality source of information" ("Getting Your Journal Indexed", n.d.), you will need to have your journal's citation metadata included in the most appropriate indexes for your discipline. Each index will have its own set of criteria for inclusion, but it generally includes:

- High quality content

- Peer-reviewed

- Compatible subject matter (for indexes focused on a single discipline)

- Recognized editorial board

- Stable publishing history

See Appendix A for links to the requirements of some of the most important commercial indexes.

For a new journal, it is impossible to demonstrate a history of stable publishing, and may make getting into many of the established, commercial indexes challenging for your first few years. The next section will look at some of the available alternatives while you build your journal's professional recognition. 


\section{Open Databases}

\section{What are Open Databases?}

Open databases are similar to commercial indexes, in that they aggregate citation metadata into a single, searchable database or listing. The main types of open databases include open indexes, directories, search engines, and open archive metadata harvesters. One of the principle advantages of open databases is that they are freely available on the Internet for anyone to use, including individual readers and libraries.

Many open databases will also be more willing to include content from new journals, placing more emphasis on the quality of your content and your open access policy than on a large archive of published material. In addition, your content can often be included more quickly in open databases.

Open databases are becoming increasingly important to researchers. While they may not yet have the same prestige or influence as some of the commercial indexes, becoming part of one or more of them will significantly raise your journal's profile with a wider audience of readers.

\section{Open Indexes}

PubMed (http://www.ncbi.nlm.nih.gov/pubmed/) is one of the most recognized and respected open indexes. As with commercial indexes, 
PubMed collects metadata from different journals (all in the field of medicine, of course) and combines them into a single, searchable database.

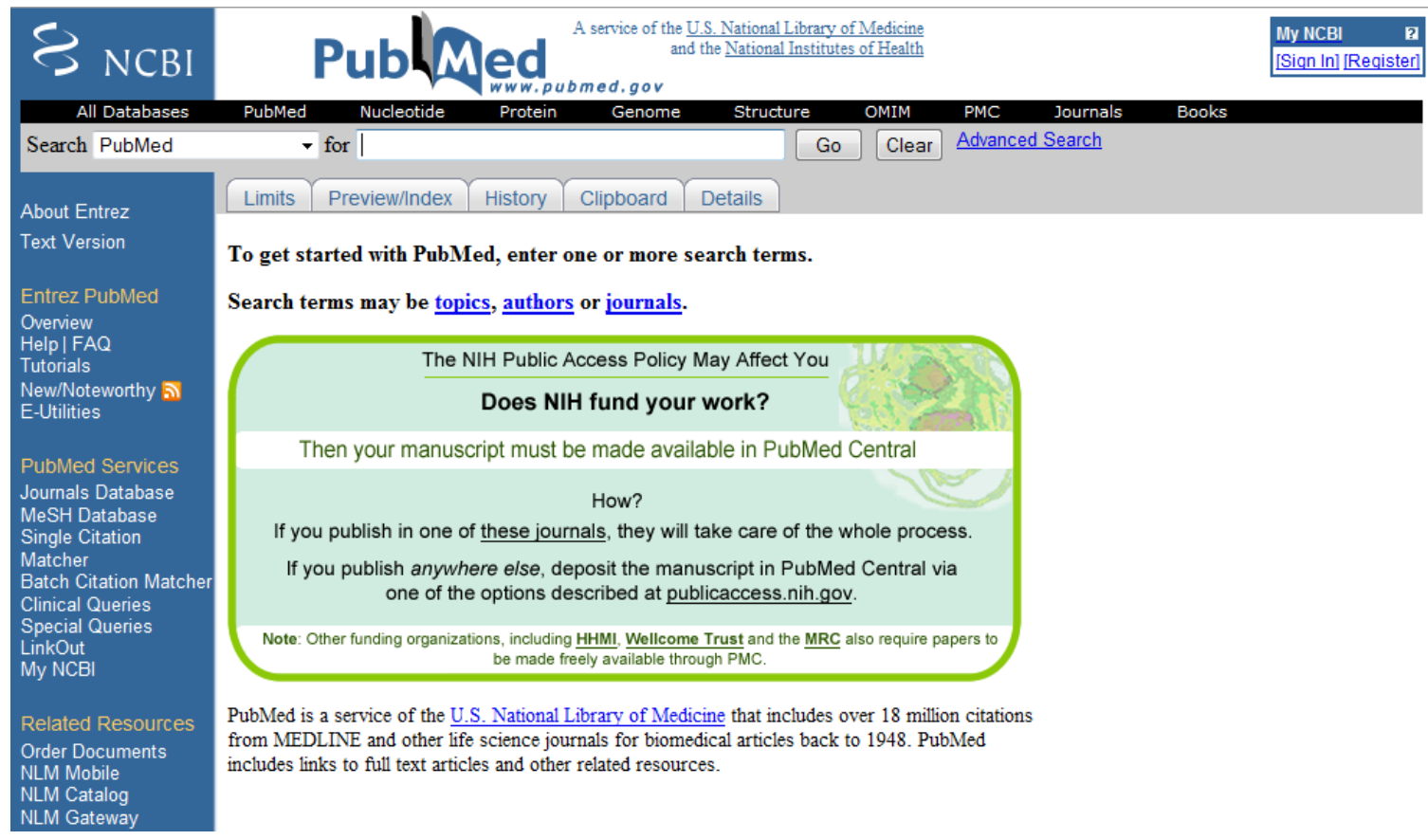

Figure 2: PubMed

The main difference is that open indexes are often publicly-funded and made freely available. OJS medical journals should certainly work to get included in PubMed. To facilitate this, OJS includes an exporting tool, which will produce a file of all of your journal's metadata, suitable for sending directly to PubMed. Some open indexes, such as BioMed Central or Chemistry Central, only include their own published content. For journals not published by BioMed Central or Chemistry Central, it is not an option. Examples of other open indexes include Agricola (http://agricola.nal.usda.gov/), from the U.S. National Agriculture Library 
and ERIC (http://www.eric.ed.gov/) sponsored by the U.S. Department of Education, Institute of Education Sciences.

\section{How to Get Indexed}

Like commercial indexes, open indexes are also looking for high quality content, peer review, compatible subject matter, and evidence of stability and sustainability. Some, however, may be willing to accept submissions from new journals lacking an established history of publication. If you do not know the best open indexes for your journal, contact your library. They will be able to guide you in the appropriate direction. See Appendix A for some examples of open index criteria.

\section{Directories}

Directories are primarily lists compiled by individuals or organizations, organized into subject areas, and made freely available on the Internet. Often directories do not offer any article-level searching capabilities, but instead are simply browsed. Like commercial and open indexes, directories are popular with libraries, because they are highly useful tools for connecting readers to appropriate content. Examples of open directories include the Directory of Open Access Journals (http://www.doaj.org/), NewJour (http://gort.ucsd.edu/newjour/), the Librarians Index to the Internet (http://lii.org/), and the Open Directory Project (http://dmoz.org/). 


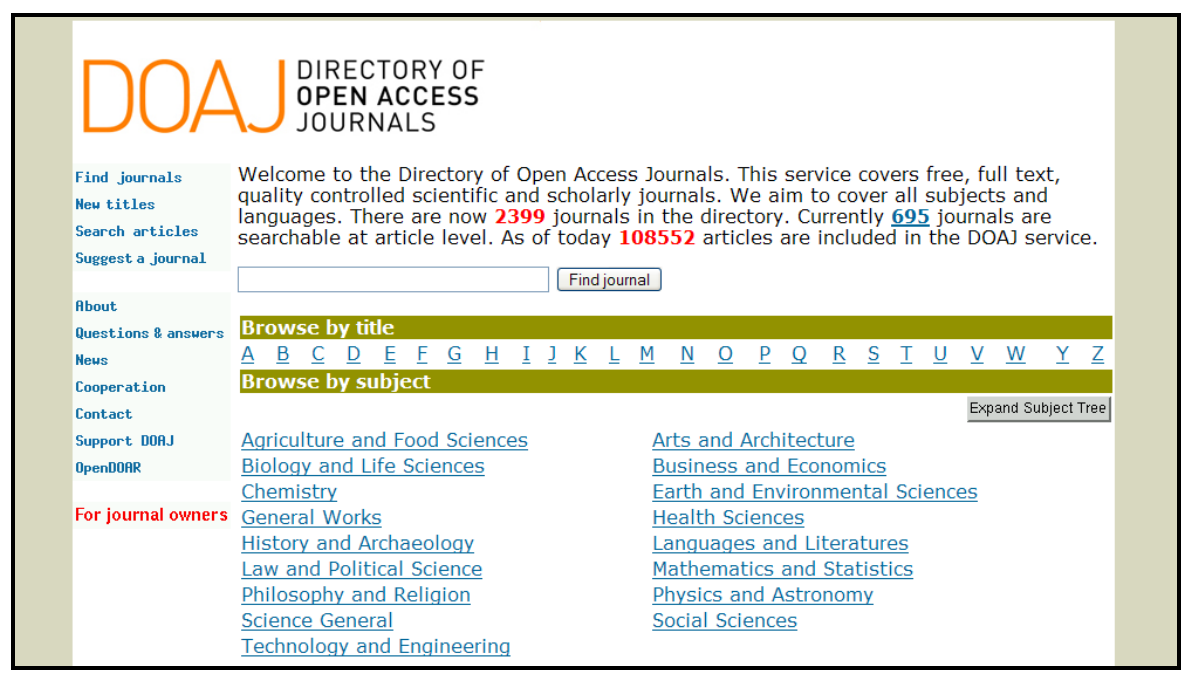

Figure 3: DOAJ

Yahoo (http://dir.yahoo.com/) was one of the original Internet

directories, but has increasingly moved toward becoming a search engine (see the next section). It does, however, continue to also be a directory.

\section{How to Get Indexed}

Contact the organizer of the directory to get your journal included. The criteria for inclusion will be similar to commercial and open indexes, but may be somewhat less demanding and more immediate. Directories are an excellent way for new journals to raise their profile, both with readers and with libraries.

Contact your local library to get included in any lists that they maintain and to find out about other directories that might be appropriate for your journal. Appendix A provides examples of inclusion criteria for some important directories. 


\section{Search Engines}

Search engines are tools used to help people find information on the World Wide Web. Using programs known as 'spiders', which 'crawl' the 'web', search engines accumulate descriptive metadata and keywords from the fulltext of various web sites and build massive, searchable indexes. Some search engines, such as Google (http://www.google.com/) attempt to cover the entire web, while others focus on a particular kind of content. Scirus (http://www.scirus.com/), for example, only indexes scientific web sites and Google Scholar (http://scholar.google.com/) only covers academic information. Microsoft's Live Academic (http://academic.live.com/) provides a similar service. Your library will be able to point you toward the best search engines for your journal to work with.

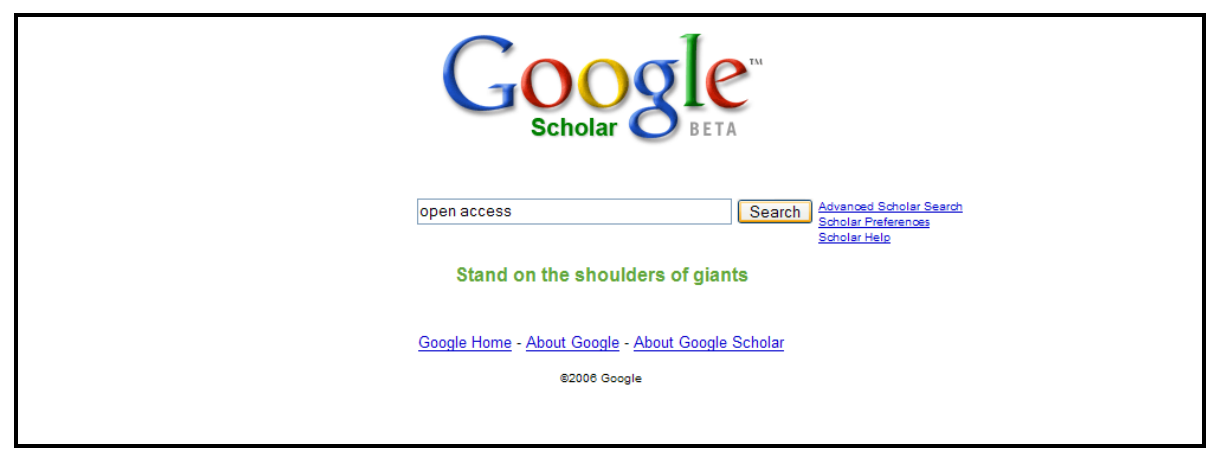

Figure 4: Google Scholar

Although no where near as sophisticated or focused as the resources previously discussed, search engines are becoming the first research choice not only for students, but for an increasing number of 
scholars as well. Getting effectively indexed in a number of search engines will go a long way toward widening your audience.

\section{How to Get Indexed}

One of the main challenges for your journal is to ensure your site is 'crawled' and indexed by the major search engines, and to make sure the indexing terms collected will be useful for helping people connect to your content. With many search engines returning hundreds of thousands of results for almost any search, you want your journal to appear as high as possible in the result list. Searchers rarely look beyond the top ten results, so improving your ranking is very important. Each search engine will have its own unique system of relevance ranking. Google Scholar, for example, "aims to sort articles the way researchers do, weighing the full text of each article, the author, the publication in which the article appears, and how often the piece has been cited in other scholarly literature" ("Support for Scholarly Publishers", 2006). Some important suggestions to improve your journal's position in a variety of search engines includes the proper use of metatags, positioning of keywords, and actively submitting your site for search engine indexing. Valuable details on these tips and more are available from Search Engine Watch (http://searchenginewatch.com/webmasters/). Help for indexing in specific search engines is also available, such as Google's Webmaster Central (http://www.google.com/webmasters/) and their support page for scholarly publishers (http://scholar.google.com/intl/en/scholar/ 
publishers.html).

\section{Open Archive Metadata Harvesters}

As the name implies, open archive metadata harvesters are tools which collect freely available metadata, and aggregate it into a single, searchable, open database. Usually operated by universities and their libraries, harvesters generally gather metadata from institutional repositories $^{1}$ and participating journals. Examples include OAlster (http://oaister.umdl.umich.edu/) from the University of Michigan, the Canadian Association of Research Library harvester (http://carl-abrcoai.lib.sfu.ca/), and the PKP harvester (http://pkp.sfu.ca/harvester2).

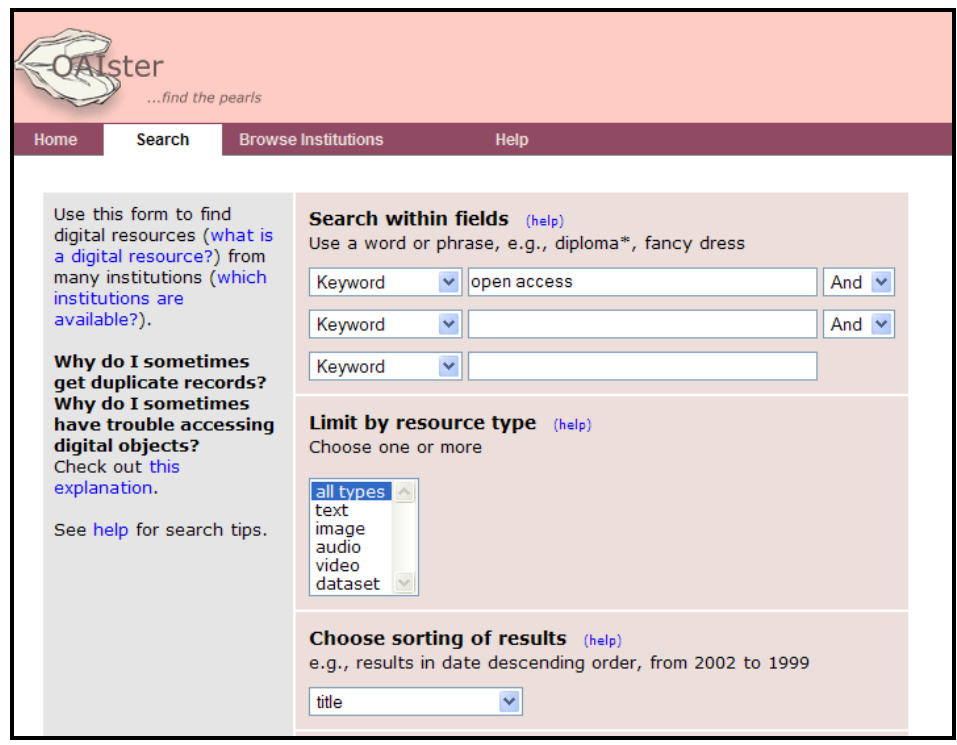

Figure 5: OAlster

1 Institutional Repositories (IRs) are online databases for collecting and preserving the online research output of institutions. DSpace (http://dspace.org) is open source IR software, used by MIT (https://dspace.mit.edu/) and many other research institutions. 
Harvesters are valuable for scholars as open resources of high quality research material.

\section{How to Get Indexed}

The easiest way to get indexed into one of these tools is to submit your metadata to the PKP Harvester. This is built right into your OJS software (see page 47 of OJS in an Hour - http://pkp.sfu.ca/files/

OJSinanHour.pdf). Contact your library to find out about other opportunities that may be available to participate in local initiatives.

\section{Libraries}

One of the fundamental objectives of libraries is to connect readers to high quality content. As a journal publisher, you will want to develop a relationship with your local library, to ensure they know about your valuable work, include your journal in their collection, and promote it to their users.

In the traditional print environment, libraries subscribe to a journal and add each physical issue to their collection. Readers visit the library, browse the journal shelves, and make choices based on what is available to them. In the online environment, with literally thousands of electronic journals that come and go, one of the challenges is getting your journal recognized and included in the library's 'virtual' collection. The virtual collection is usually made available through the library's online catalogue 
or electronic journal database (e.g., Simon Fraser University's electronic journal database - http://cufts2.lib.sfu.ca/CJDB/BVAS/).

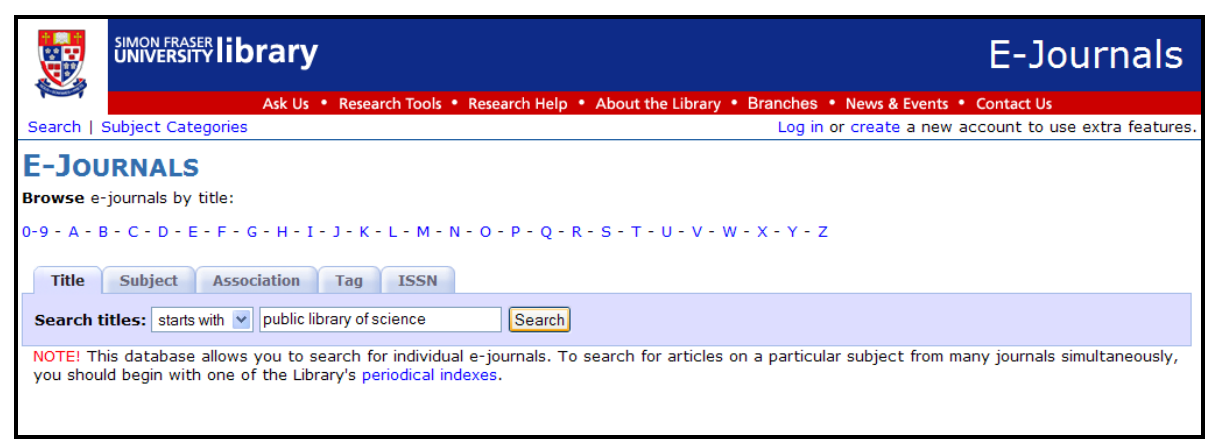

Figure 6: Electronic Journal Database

Online catalogues and journal databases allow readers to browse or search for appropriate content for their research, and allow for direct linking (to your journal or your articles) into online educational resources such as course web pages, or course management systems, including WebCT (http://www.webct.com/) or Moodle (http://moodle.org/).

The most straightforward way to get your journal included in a library's virtual collection is to simply ask, letting them know about your project, and the audience you are trying to reach. Libraries are very open to collaboration and would welcome your request and the information you could provide. Another way to ensure you are part of many library collections is to become part of a larger journal entity, such as one of the open directories mentioned earlier. Most libraries provide links to the DOAJ, for example, and the DOAJ provides libraries with a list of titles to download and repurpose on their own web sites. Participating in any local metadata harvesting initiatives (such as the Synergies project in Canada http://www.synergies.umontreal.ca), institutional repositories, or 
directory projects could also help your journal get recognized as part of a library's virtual collection.

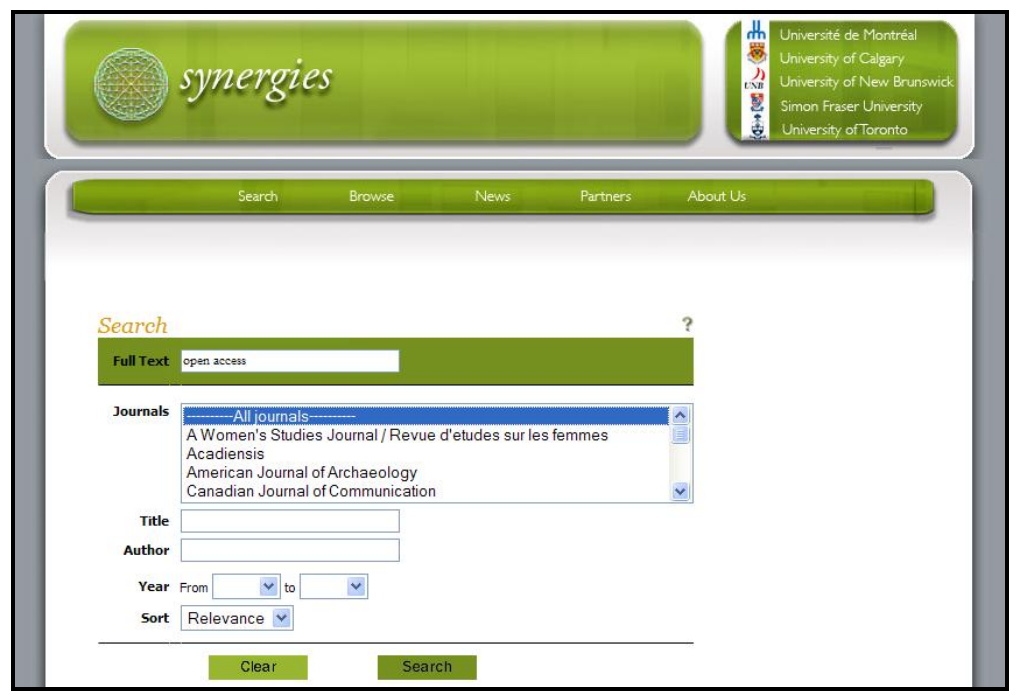

Figure 7: Synergies

Another reason to work with your local library is to access information you will need to widen the reach of your journal. In the previous sections, this booklet outlined many ways in which libraries can help you find out about indexes, directories, repositories, harvesters, and other tools and services that can let prospective readers find you more easily.

\section{The Media}

Communicating with the media is another important way of getting the word out about your journal. A press release is "a written or recorded communication directed at members of the news media for the purpose of announcing something claimed as having news value" ("News Release", 
2006). Writing an effective and professional press release will help the media to understand your message, putting it into a format they can use.

\section{How to Write a Press Release}

To be effective, a press release should be concise and have a clear focus. The majority of press releases are 500 words of text organized into four or five, short two to three sentence paragraphs. All of the essential information (who, what, where, when, and why) should appear in the first paragraph. It should also follow an established format, including:

1. Add the words "FOR IMMEDIATE RELEASE" in the top left-hand margin in all caps. Follow this line with relevant contact information: name, title, address, phone number, e-mail address. If you have a logo for your journal, include it as a letterhead.

2. Create a headline and center it in bold type just above the first line of the body of the press release. Headlines typically highlight the most significant fact in the release.

3. Include a dateline - the first line of the body of your press release with the city where the release is generated and the date (e.g., VANCOUVER, BC - December 31, 2006).

4. Use block style, without paragraph indentations.

5. The last paragraph should end with a "for additional information" line, indicating a location to find more details. Your web site is an obvious source of information for this. 
6. Finally, centre these marks: "\# \# \#" or "-30-", at the bottom of the page to indicate the end of your release.

See Appendix B for a sample press release.

\section{How to Distribute a Press Release}

To most effectively distribute your press release, you will want to target the most appropriate media for your message. For example, a press release announcing the launch of your journal would be welcomed by other related professional or scholarly publications, but would probably not be used by the popular media (television, radio, magazines, or newspapers). However, if you are publicizing a major new discovery or research finds on a topic of more general interest, the popular media may be interested. Targeting your press releases is the key to the successful distribution of your press releases. Once again, be sure to make use of your library to find out about all of the potential media outlets for your press releases.

\section{Professional Networks}

In addition to the formal methods of informing others about your journal, are also the more informal means of getting the word out. Included in these is the obvious need to simply tell people about your work. Any opportunity that presents itself, whether at professional meetings, conferences, or other functions, should be taken advantage of. Don't overlook easy ways to market your journal, such as by adding your 
journal's web site address to your email signature. This will make every message you send into an opportunity to let others know about your project.

Other ways to share information about your journal's activities are through the various professional listservs and blogs that are appropriate to your subject area.

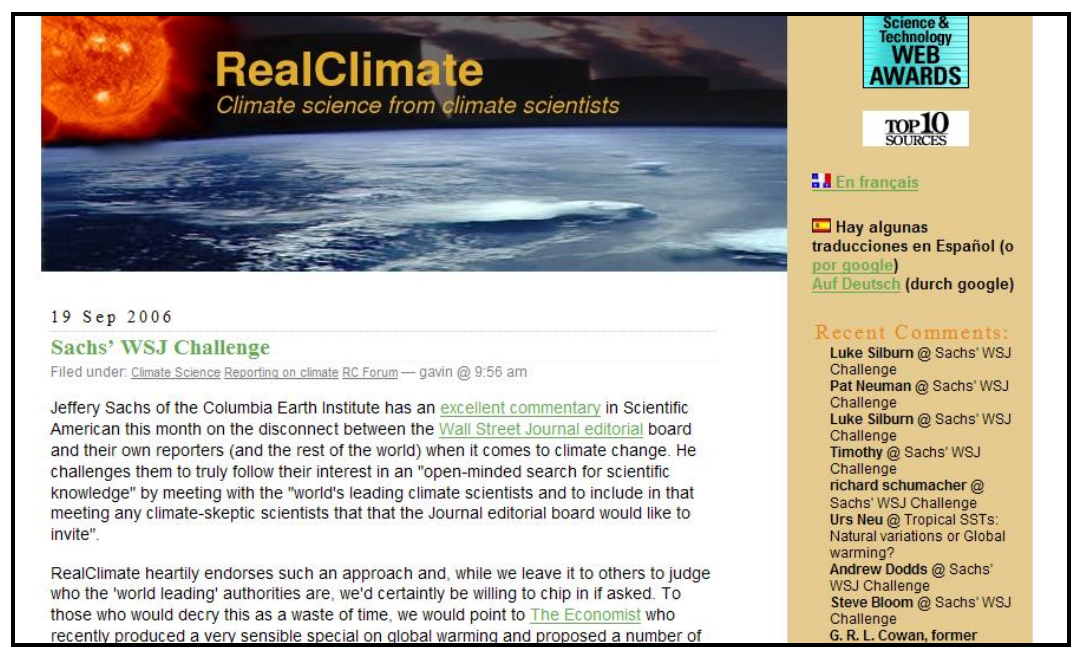

Figure 8: RealClimate - Scientific Blogging

These electronic information networks have become wildly popular on the Internet, and are making increasing inroads into scholarly communications.

\section{Professional Recognition}

All successful academic journals are based upon a solid foundation of professional recognition. Being recognized and respected by your peers encourages their participation (as readers, authors, reviewers, editors, and board members). It helps to overcome any reluctance to get involved 
with your journal, easing fears that they may be wasting their valuable time and effort on their road to securing tenure or building their own careers. Professional recognition also builds confidence in the different indexing and database services to include your content, and in libraries willingness to promote your publication.

\section{Challenges for New Journals}

Fostering professional recognition is always a challenge, and can be especially difficult for a new journal, with no archive of high quality content to point to. There are, however, some important first steps that can be taken to assist with this process.

First, your journal must develop a professional layout, for both your web site and your articles. Web-based interfaces have become extremely sophisticated and, whether accurate or not, amateur designs tend to reflect amateur efforts. The Open Journal Systems software provides a strong template for your journal, but enlisting the services of a professional graphic designer to give it a fresh, unique look can be a very important step in building respect and recognition. Second, ensure that your journal is being hosted on a secure, professionally managed server. Your content must be online and available at least $99.9 \%$ of the time. Frequent downtime reflects an amateur effort. This booklet deals with servers and preservation in the following section. Third, try to encourage the participation of recognized colleagues as editorial board members or authors, and be sure to make their involvement in your project visible. 
Fourth, make use of the OJS peer review system and let your audience know that your journal is following the established guidelines for ensuring high quality content. Fifth, provide open access to your content, to allow a much wider audience to freely and immediately see the value of your project.

Once your journal has begun publishing, it is critical that you maintain a reliable publication schedule. If your journal publishes quarterly, you must produce four issues a year, even if this means fewer articles per issue. Anything less reflects a lack of professionalism. If you are unsure about your ability to sustain a quarterly journal, start out with a semi-annual or even an annual journal.

Although it sounds obvious, it is important to remember that you should only be accepting the highest quality submissions to your journal. Again, this may mean fewer articles per issue, but producing and sharing high quality scholarly information is at the heart of your project.

\section{Measuring Your Impact}

Another method of building professional recognition is through the use of different techniques for measuring the use and impact of your journal. This will provide clear evidence of the success of your journal and allow you to regularly evaluate your progress.

With the traditional subscription model, the number of subscribers often formed the basis for understanding the usage of an individual journal. For open access journals, without a subscriber base to point to, 
this can be a challenge. OJS, however, does provide the option of requiring readers to register. A fee is not necessarily required for this registration, but does allow the journal to develop a better understanding of its audience. Some statistical analysis and reports are available to the OJS Journal Manager, including reporting on the number of registered users.

Another way to measure usage is through the analysis of web logs. These are records produced by the server hosting your journal which counts the number of times your journal is visited. Details such as the geographic location of the reader are also available. While web logs cannot measure whether someone briefly visited your site for ten seconds or became involved in some sustained reading for an hour or more, they do provide some understanding of use, can provide comparisons to previous months or years, and can provide some data for evaluating your impact.

Perhaps more important than the question of how many people are accessing your journal is how they are using it. This is known as measuring the "impact" of your journal. Journals with high citation impact are among the most respected and successful academic journals in their fields. Citation impact refers to how often an article, an author, or a journal, is cited by other scholars ("Citation Impact", 2006). While this is not an uncontroversial means of measuring the value a journal is having in the academic community, it is the standard one that most people 
recognize and operate on the basis of. Readers looking for reliable information will often first look to journals with a high citation impact. Prospective authors, reviewers, and editors will be interested in volunteering their time with journals that have a high citation impact. Indexes and databases will want to include journals in their resources that have a high citation impact. And lastly, libraries will be motivated to promote journals with a high citation impact. All of this can lead to a cyclical pattern, where high impact journals are more likely to be used and supported, leading to more recognition, and higher impact. The challenge for every new journal is to get this process started, using some of the methods discussed in the previous section.

Of particular interest for OJS and other open access journals are the results from several studies revealing that open access policies tend to increase the citation impact of journals ("Bibliography of Empirical Studies on Open Access", 2006). By providing free and immediate access to their content, open access journals are increasingly becoming the first choice among scholars for their research.

\section{Journal Standards and Identifiers}

\section{International Standard Serials Number}

Another way of helping people find your journal, and helping libraries manage and promote it, is to obtain an International Standard Serial Number, or ISSN. An ISSN is an eight digit, "standardized international 
code which allows the identification of any serial publication, including electronic serials, independently of its country of publication, of its language or alphabet, of its frequency, medium, etc." ("International Standard Serial Number", 2006). ISSNs are widely used by libraries, citation indexes, and the publishing industry to uniquely identify journals, and are often more important than the journal title itself for serials management. Every serious journal has an ISSN, and one can be obtained free of charge from a local ISSN Centre (http://www.issn.org/ en/flexinode/table/1). An example of an ISSN is "1544-9173" for the journal Public Library of Science Biology. The OJS Journal Manager can enter the ISSN in the Setup of the journal.

\section{Digital Object Identifiers}

In addition to an ISSN, you may also consider obtaining a Digital Object Identifier (DOI) for your journal. A DOI is another standardized code, allowing libraries, citation indexes, and the publishing industry to discover your content. DOIs differ from ISSNs, however, in that they only apply to electronic information and that they uniquely identify each of your articles as well as your journal. It is important to note that even if you changed your server, renamed your journal, or even moved off of the OJS system, your DOIs would not change, providing readers with a persistent URL to your content, which is important for reliable linking into course management systems, library-created article lists, and readers' electronic bibliographies. This is an important advantage over URL 
linking, which is notorious for changing in the online environment. An example of a DOI is " $10.1371 /$ journal.pbio.0040176", for the article "Open Access Increases Citation Rate" in the journal Public Library of Science Biology. When the prefix "dx.doi.org/" is added to the DOI, a persistent URL is created:

http://dx.doi.org/10.1371/journal.pbio.0040176

Entering this URL into your Internet browser will always take you directly to this article.

Although not as common as ISSNs, DOIs are increasingly being used for advanced library services such as link resolving (also known as citation or reference linking). ${ }^{2}$ It is important to note that DOls require the payment of an annual fee. Applications can be made to CrossRef (http://crossref.org), a not-for-profit network of publishers. Like the ISSN, your DOI can be added to OJS by the Journal Manager in the Setup options. You will also need to regularly submit your journal's metadata to CrossRef and determine a structure for your article-level DOls. See the CrossRef publisher site for further details: http://www.crossref.org/ 02publishers/index.html. Although not as crucial as the ISSN, the benefits of using DOIs for persistent linking are worth considering. If you decide against it for your startup journal, consider revisiting this option

\footnotetext{
2 Link resolving provides a web-based link between a citation in an index and the fulltext of the content referred to in the citation.
} 
once you have become more established. DOIs provide yet another powerful tool for connecting your content with readers. 


\section{Staying Found: Building Reliable and}

\section{Ongoing Content}

Once your journal has developed a loyal readership, and established itself with a variety of indexes and databases, you will need to be able to maintain these relationships. One of the fastest ways to undermine the confidence in your publication is if your content becomes regularly unavailable, or worse, disappears completely.

For print journals, reliable access is helped by the production of many physical copies of the journal, and their widespread distribution. If one copy is lost or misplaced, it can easily be replaced by a copy of another.

For online content, there is the danger of there being only a single copy, which is shared electronically among all readers over the Internet. If that single copy is lost, it is irreplaceable, and the results can be catastrophic for your project.

\section{Finding the Right Server}

Ensuring that your journal is hosted on a secure and reliable server is the first step to providing uninterrupted access to your content. A server is simply a computer that can not only view files on the Internet, but can also let others (securely!) see its own files. Every website that you visit is 
stored (or "hosted") on a computer acting as a web server. Some institutions have their own web servers that you may be able to use, or you may need to investigate the services of a commercial provider. Choosing a high quality web server is an important step in setting up an online journal, so you will need to ask some hard questions.

Is the service reliable? You will have people wanting to visit your site frequently and at different times of the day. A good host should be able to guarantee 99 - 99.5\% uptime, 24 hours a day, 7 days a week.

Speed is another important issue. Does the service have a powerful connection to the backbone of the Internet? Ideally, they will be able to provide what is known as a T3 connection (very fast), but a T1 connection (less fast) is the minimum.

Does the host support the web-based software you will require? For OJS, you will need to ensure all of the following are available:

- $\mathrm{PHP}>=4.2 . \mathrm{x}$

- $\mathrm{MySQL}>=3.23 .23$ (including 4.x) or PostgreSQL $>=7.1$

- Apache $>=1.3 .2 \times$ or $>=2.0 .4 x$ or Microsoft IIS $6+$

You will also want to make sure that these programs are updated when new versions are released.

Does the service provide enough space on the server for your journal? It may not seem important now, but with years of accumulated PDF documents, or possibly even audio or video files, you will need at 
least 1 Gigabytes of storage space. More is better. Find out the cost of increasing your storage space as your needs expand.

Does the service provide daily backups? If something happens to your site, you will want to be able to restore it back to where it was before the problem occurred. Is the database also backed up? If you are running OJS or any other database-driven applications, you will want to make sure the database can also be restored in the event of a system failure.

Does the provider have a system in place for their own system failures, such as power loss or server crashes? Will they be able to have your site back online fast after such a crisis?

Technical support is another important factor to consider. If you need assistance, will there be someone available in a timely manner with the required expertise? Ask some technical questions now, and see how long it takes to receive a response. If they can't answer your questions quickly now, will you be able to rely on them when you are facing a system crisis?

Finally, investigate their current list of customers, and contact some of them to ensure they are satisfied with the service they are receiving. This may all seem like a great deal of effort, but mistakes here can be costly and time consuming in the future. Frequent downtime (or permanently lost content!) undermines the relationship that you are establishing with your collaborators. 


\section{LOCKSS (Lots of Copies Keeps Stuff Safe)}

Once your journal is set up on a secure and reliable server, you will still want to make sure you have an emergency preservation strategy in place. Unlike print publishing, where multiple copies are produced, distributed, and maintained by libraries, electronic journals often produce only a single electronic file (or set of files), which are accessed by multiple readers over the Internet. If this single file is lost, due to a system failure or human error, and no reliable backup exists, all of your work, and the work of your collaborators could simply disappear - permanently. To help online journal publishers overcome this potential disaster, Stanford University developed the open source LOCKSS project (Lots of Copies Keeps Stuff Safe). LOCKSS consists of geographically distributed servers maintained by libraries, the traditional experts in information storage and preservation. LOCKSS ensures that multiple copies of your content exists on a network of servers, that all of your latest content is collected and securely stored by a specialized web crawler (similar to those used by search engines), is continually examined for lost or damaged content, and makes any necessary repairs. Further details on how this system works is available on the LOCKSS website (http://www.lockss.org/).

Fortunately for publishers using OJS, the software has LOCKSScompliance built into the system, and your journal can easily take advantage of this effective preservation strategy through the Journal 
Manager menu (see page 40 of OJS in an Hour). It is one easy step toward disaster prevention for your journal. 


\section{Conclusion}

Creating a successful scholarly or scientific journal requires careful attention to the collaborations that develop out of your project. This booklet outlined how to get started in working with indexing and listing services to highlight your journal, with the media to inform more people about your publication's activities, and with libraries, to promote your content, and to inform you about other tools and services that might be available to expand your audience even further.

All of this, of course, is intended to help you find more readers, or, perhaps more accurately, help more readers find you, the virtual needle in the world wide haystack. Once they have found you, your readers will need to be able to keep on accessing your content. The second part of the booklet discussed the importance of maintaining your online presence, through the use of reliable hosting services and the LOCKSS preservation system. By building valuable, open, online content, by making it easily 'findable', and by ensuring its long-term availability, you will be respecting the investment of time and effort made by your readers and other collaborators, and helping to ensure your projects ultimate success. 


\section{References}

Bibliography of Empirical Studies on Open Access. (2006). Wikipedia.

Retrieved October 23, 2006, from http://en.wikipedia.org/wiki/

Open_access\#Bibliography_of_Empirical_Studies_on_Open_Access

Citation Impact. (2006). Wikipedia. Retrieved October 23, 2006, from

http://en.wikipedia.org/wiki/Citation_impact

Getting Your Journal Indexed. (n.d.). Scholarly Publishing and Academic

Resource Coalition. Retrieved October 23, 2006, from

http://www.arl.org/sparc/resources/ji.html

International Standard Serial Number. (2006). ISSN International Centre.

Retrieved October 23, 2006, from http://www.issn.org/en/

node

News Release. (2006). Wikipedia. Retrieved October 23, 2006, from

http://en.wikipedia.org/wiki/News_release

Support for Scholarly Publishers. (2006). Google Scholar. Retrieved

October 23, 2006, from http://scholar.google.com/intl/en/scholar/

publishers.html 


\section{Appendix A: Indexing Criteria}

The following list provides links to a selection of indexing and listing services and their criteria for inclusion. Contact your library for information about other indexes and databases that are available.

\section{Commercial Indexes}

Alternative Press Index - Multidisciplinary

http:/ /www.altpress.org/criterial.html

\section{Biosis - Biology}

http://thomsonscientific.com/support/faq/biosis/\#submitjournal

\section{CAB Abstracts - Sciences}

http:/ / www.cabi-publishing.org/AbstractDatabases.asp?

SubjectArea $=\&$ Subject $=\&$ Section $=$ ss $\&$ PID $=125$

EBSCO - Multiple indexes in a variety of research areas

http:/ / www.epnet.com/thisTopic.php?marketID=21\&topicID=236

\section{EconLit - Economics}

http:/ / www.econlit.org/corr.html

\section{GeoRef - Geography/Earth Sciences}

http://www.agiweb.org/georef/index.html

Institute for Scientific Information - Sciences

http://www.scientific.thomson.com/mjl/selection/ 
MLA Bibliography - Language, lingustics, and literature http://www.mla.org/bib_inclusion

Philosopher's Index - Philosophy

http://www.philinfo.org/policies.htm\#newjournals

Proquest - Multiple indexes in a variety of research areas

http://www.proquest.com/publisher/pub-partner.shtml

Psyclnfo - Psychology

http://www.apa.org/psycinfo/publishers/journals.html

Scopus - Multidisciplinary

http://info.scopus.com/etc/suggesttitle/

\section{Open Indexes}

AgeLine - Gerontology

http://www.aarp.org/research/ageline/about.html

Agricola - Agriculture

http://www.nal.usda.gov/AGRICOLA/agricolaMail.html

ERIC - Education

http://www.eric.ed.gov/ERICWebPortal/resources/html/news/ERIC \%20Selection\%20Policy.pdf

PubMed - Health Sciences

http://www.ncbi.nlm.nih.gov/pubmed/

\section{PubMed Central - Health Sciences}

http:/ /www.pubmedcentral.nih.gov/about/pubinfo.html 
RePEc

http://ideas.repec.org/stepbystep.html

\section{Open Directories}

Directory of Open Access Journals

http:/ / www.doaj.org/articles/about\#criteria

Librarians Internet Index

http://lii.org/cs/lii/create/todo

New Jour

http://gort.ucsd.edu/newjour/

\section{Open Directory Project}

http://dmoz.org/add.html

Open J-Gate

http:/ /www.openj-gate.com/

Yahoo

https://ecom.yahoo.com/dir/submit/intro/

\section{Search Engines}

\section{Academic Live}

http://academic.live.com/AcademicPublishers.htm

\section{CiteSeer}

http://citeseer.ist.psu.edu/submitDocument.html

\section{Google}


http://www.google.com/intl/en/submit_content.html

Google Scholar

http://scholar.google.com/intl/en/scholar/publishers.html

\section{Scirus}

http://www.scirus.com/srsapp/submiturl/

\section{Open Archives Harvesters}

\section{Canadian Association of Research Libraries}

http://carl-abrc-oai.lib.sfu.ca/service_provider.php

\section{OAlster}

http://oaister.umdl.umich.edu/o/oaister/dataproviders.html

\section{PKP Harvester}

http://pkp.sfu.ca/harvester2/demo/index.php/add 


\section{Appendix B: Sample Press Release}

FOR IMMEDIATE RELEASE

Contact:

Jane A. Smith, PhD

Editor, New Journal of Chemistry

123 University Drive

Vancouver, BC, Canada V7V 7V7

Phone: 604-987-6543

http://www.newchemistryjournal.org

info@newchemistryjournal.org

Important New Chemistry Journal Launched: New Journal of Chemistry

Vancouver, BC - September 12, 2007 -- Lorem ipsum dolor sit amet, consectetuer adipiscing elit. Nam tincidunt. Quisque a neque. Cum sociis natoque penatibus et magnis dis parturient montes, nascetur ridiculus mus. Integer laoreet elit nec lorem. Cum sociis natoque penatibus et magnis dis parturient montes, nascetur ridiculus mus. Vestibulum ac dolor.

Sed vitae tellus nec sapien malesuada mattis. Etiam molestie laoreet enim. Vestibulum tempus pretium tellus. Sed mauris. Morbi urna. Quisque varius risus in dolor. Fusce bibendum sagittis risus. Proin sapien erat, iaculis nec, lobortis vitae, ultricies nec, orci. Vivamus auctor adipiscing lectus. Nulla pulvinar feugiat risus. Nullam et massa non purus eleifend lobortis.

Integer et libero a purus volutpat cursus. Nullam ut eros sit amet felis rhoncus condimentum. Integer fermentum ligula. Sed mauris libero, varius rhoncus, vehicula nec, vestibulum vel, mauris. In hendrerit. Etiam id justo at leo fringilla fermentum. Etiam ullamcorper, nibh et varius cursus, tellus massa eleifend lectus, et consectetuer lorem pede eget purus.

For information: http://www.newchemistryjournal.org Contact: info@newchemistryjournal.org

Phone: 604-987-5432 